\title{
The Inauguration of Asian Pacific Journal of Environment and Cancer
}

\section{Saeed Yari ${ }^{1}$, Alireza Mosavi Jarrahi}

${ }^{1}$ Department and Faculty of Health, Shahid Beheshti University of Medical Sciences, Tehran, Iran. ${ }^{2}$ Medical School, Shahid Beheshti University of Medical Sciences, Tehran, Iran.

\begin{abstract}
On behalf of the Asian Pacific Organization for Cancer Prevention (APOCP) and its subsidiary (the West Asia Organization for Cancer Prevention- WAOCP), it is a great honor to present the inaugural issue of Asian Pacific Journal of Envirinment and Cancer (APJEC). APJEC is separated from the Asian Pacific Journal of Cancer Prevention and is determined to become a leading journal for scientists and researcher of the world. APJEC inherited its activity from the 19-year body of the successful publication of the Asian Pacific Journal of Cancer Prevention (APJCP) and considers itself to be the APJCP sister publications.
\end{abstract}

Keywords: Occupational cancer- environmental cancer- APJEC

Asian Pac J Environment and Cancer, 1 (1), 1-3

\section{Introduction}

By increasing the production and use of chemicals, the risk of exposure to material was increase [1]. Thus, people are exposed to various chemicals throughout their lives, and in particular their Occupational and environmental areas [2]. Hence, environmental pollution is one of the major causes of disease, death and disability in the countries of the world [3]. Chemicals and their compounds cause cancer in humans [4]. The first factor in occupational and environmental carcinogens was discovered in 1775 by Pott [5]. According to the WHO / IARC, the cancer kills 8.2 million people each year, and each year 14 million new cancers are detected. Until 2035, if control conditions are fixed. It is expected that deaths will increase by $78 \%$ and the incidence will increase by $70 \%$. In 2013, 1.314 million cancer deaths are estimated in the European Union, that its casualties is more than the number of deaths from HIV / AIDS, malaria and tuberculosis [6-7], which is largely due to air pollution in the environment and work environment [8]. The International Labor Organization (ILO) estimates 666,000 deaths from occupational cancer worldwide every year, twice as much as occupational accidents [9].
Submission Date: 06/08/2018 Acceptance Date: 08/13/2018

\section{Results}

Since cancer is a multifaceted disease, it is difficult to identify some of the factors that make it. But it is clear that work-related cancer can be prevented by reducing or eliminating occupational and environmental exposures [10-11]. Therefore, occupational cancers can usually be reduced or even eliminated. Lung cancer accounts for $54 \%$ to $75 \%$ of total occupational cancer. Asbestos is the main cause of $55-85 \%$ of lung cancers that could have been prevented in the past. The deaths from cancer and occupational cancer have increased due to an increase in life expectancy and a gradual reduction in other causes of death, such as infectious diseases and injuries. Occupational cancers are rapidly globalizing and in many industrialized countries, mortality rates for occupational cancer are high among all the deaths associated with work. So that, currently in the European Union, mortality from occupational cancer accounts for $53 \%$ of all work-related deaths (Figure. 1)[12].

Air pollution, outdoor and indoor, is an important environmental health issue in developed and developing countries. Volatile organic compounds, organic compounds containing nitrogen and halogenated, polycyclic aromatic hydrocarbons (PAHs), toxic metals, pesticides, lead, aflatoxins, dioxins and many poorly combustible products 


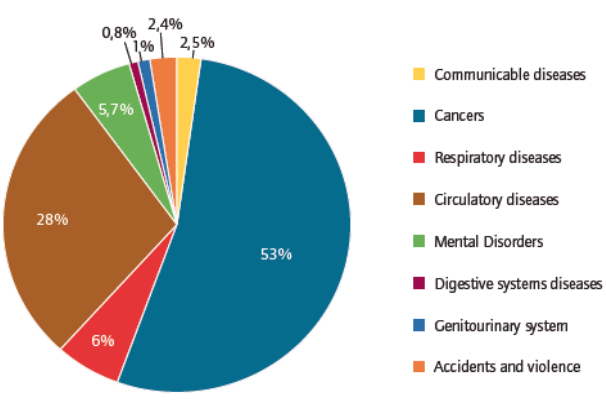

Figure 1. Annual Work-related Deaths in the EU and other Developed Countries

(eg dioxins), all are carcinogenic substances that infecting the air [13-14]. Other environmental factors that contribute to cancer include: tobacco smoking [15], ionizing and nonionizing radiation [16], sedentary work [17], stress, shift working, heat shock, biological agents, nanomaterials [4], asbestos [18], radon [19], arsenic in drinking water [20], lack of exercise and sports activities [8]. In the following, the most common environmental carcinogens in the UK are shown.

The incidence of cancers varies from country to country [21-22]. Consequently, cancer control programs should rely on statistics of the prevalence of cancers in each country [23]. Twenty-five years ago, the European Union adopted its first global directive to improve cancer prevention in the workplace [12]. The Asia and Pacific also have a large part of the world's population with different ethnicities and religions that live in different geographic areas. In the second half of the twenty-first century, countries in the region have had rapid economic growth that continues today, and has led to major changes in people's lifestyles and exposure to occupational risk factors and cancerous environments [23]. With industrial progress and economic development, air quality in Asian countries has become worse, and air pollution has become a concern in outdoor. For example, levels of PAHs in large Asian cities are high compared to western countries [24]. Due to problems in proving causality, and the duration of exposure to carcinogens, there is no available information on the actual rate of occupational cancer [25]. To estimate the level of occupational cancer, we need to use indirect methods to determine how much

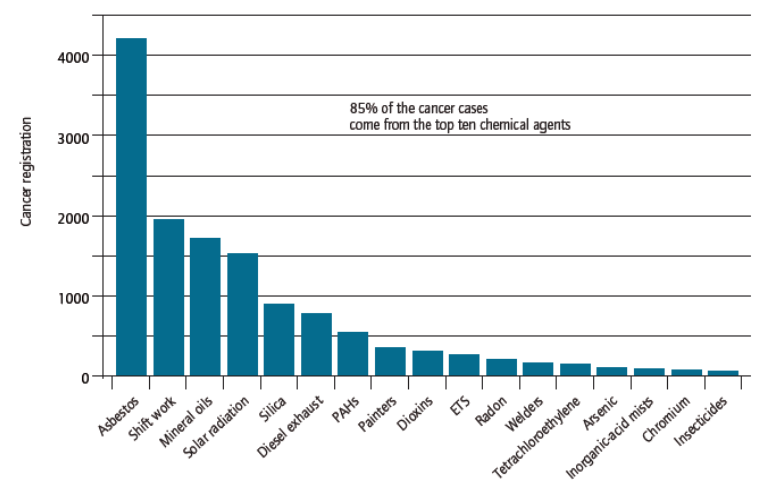

Figure 2. The Most Common Carcinogens and Exposure to Work in the UK cancers are due to occupation and the environment. On the other hand, the health consequences of exposure to environmental pesticides are major and growing problems. But they did not pay enough attention, and now it's time to attract the world's attention to the global and environmental issue. Pollution of any kind requires attention such as infectious diseases and the global response to contamination requires the same degree of difficulty that applies to AIDS, tuberculosis and malaria. The international community's focus on environmental pollution can save millions of lives [3].

In conclusion, on behalf of the Asian Pacific Organization for Cancer Prevention (APOCP) and its subsidiary (the West Asia Organization for Cancer Prevention- WAOCP), it is a great honor to present the inaugural issue of Asian Pacific Journal of Envirinment and Cancer (APJEC). APJEC is separated from the Asian Pacific Journal of Cancer Prevention and is determined to become a leading journal for scientists and researcher of the world. APJEC inherited its activity from the 19-year body of the successful publication of the Asian Pacific Journal of Cancer Prevention (APJCP) and considers itself to be the APJCP sister publications.

\section{References}

1. Yari, S., A. A. Fallah and S. Varmazyar (2015). "Assessment of semi-quantitative health risks of exposure to harmful chemical agents in the context of carcinogenesis in the latex glove manufacturing industry.” Asian Pacific journal of cancer prevention: APJCP 17: S3.

2. Mosavi-Jarrahi, A., M. Mohagheghi, B. Kalaghchi, Y. Mousavi-Jarrahi and M. K. Noori (2009). "Estimating the incidence of lung cancer attributable to occupational exposure in Iran." Population health metrics 7(1): 7.

3. Landrigan, P. J., J. L. Sly, M. Ruchirawat, E. R. Silva, X. Huo, F. Diaz-Barriga, H. J. Zar, M. King, E.-H. Ha and K. A. Asante (2016). "Health consequences of environmental exposures: changing global patterns of exposure and disease." Annals of global health 82(1): 10-19.

4. Lissner, L., K. Kuhl, T. Knaupinen and S. Uuksulainen (2014). "Exposure to carcinogens and work-related cancer: A review of assessment methods." European Risk Observatory Report; European Agency for Safety and Health at Work: Luxembourg: 1-64.

5. Melicow, M. M. (1975). "Percivall Pott (1713-1788) 200th anniversary of first report of occupation-induced cancer of scrotum in chimney sweepers (1775)." Urology 6(6): 745-749.

6. Hashim, D. and P. Boffetta (2014). "Occupational and environmental exposures and cancers in developing countries." Annals of global health 80(5): 393-411.

7. Organization, W. H. (2014). "Data on the size of the HIV/ AIDS epidemic: Number of deaths due to HIV/AIDS." Global Health Observatory Data Repository. WHO, Geneva.

8. Prüss-Üstün, A. and C. Corvalán (2006). "Preventing disease through healthy environments." Towards an estimate of the environmental burden of disease. Geneva: World Health Organization.

9. Hämäläinen, P., J. Takala and K. L. Saarela (2007). "Global estimates of fatal work-related diseases.” American journal of industrial medicine 50(1): 28-41.

10. Doll, R. and R. Peto (1981). "The causes of cancer: quantitative estimates of avoidable risks of cancer in the 
United States today.” JNCI: Journal of the National Cancer Institute 66(6): 1192-1308.

11. Shrivastava, S. R., P. S. Shrivastava and J. Ramasamy (2014). "Occupational cancer: Public health interventions to minimize its burden and impact on the society." Iranian journal of cancer prevention 7(2): 111.

12. Takala, J. (2015). "Eliminating occupational cancer in Europe and globally.

13. Park, S., J. Bae, B.-H. Nam and K.-Y. Yoo (2008). “Aetiology of cancer in Asia." Asian Pac J Cancer Prev 9(3): 371-380.

14. Organization, W. H. (2011). "An overview of the evidence on environmental and occupational determinants of cancer." Asturias, Spain: 1.

15. Mosavi-Jarrahi, A., M. Mohagheghi, B. Yazdizadeh, A. Kolahi, S. Tahmasebi and S. Sharifi (2004). "Analysis of smoking behaviour among Iranian population: a cohort and period analysis." Asian Pacific journal of cancer prevention: APJCP 5(1): 66-69.

16. Clapp, R. W., M. M. Jacobs and E. L. Loechler (2008). "Environmental and occupational causes of cancer: new evidence 2005-2007." Reviews on environmental health 23(1): 1-38.

17. Boyle, T., L. Fritschi, J. Heyworth and F. Bull (2011). "Long-term sedentary work and the risk of subsite-specific colorectal cancer." American journal of epidemiology 173(10): 1183-1191.

18. WHO, J. (2009). Global health risks: mortality and burden of disease attributabbl to selected major risk, Geneva: WHO.

19. Li, P., S.-S. Deng, J.-B. Wang, A. Iwata, Y.-L. Qiao, X.-B. Dai and P. Boffetta (2012). "Occupational and environmental cancer incidence and mortality in China." Occupational medicine 62(4): 281-287.

20. Lokuge, K. M., W. Smith, B. Caldwell, K. Dear and A. H. Milton (2004). "The effect of arsenic mitigation interventions on disease burden in Bangladesh." Environmental Health Perspectives 112(11): 1172 .

21. De Maio, F. G. (2011). "Understanding chronic noncommunicable diseases in Latin America: towards an equitybased research agenda." Globalization and health 7(1): 36 .

22. Barreto, M. L. (2004). "The globalization of epidemiology: critical thoughts from Latin America.” International Journal of Epidemiology 33(5): 1132-1137.

23. Roshandel, G., M. Boreiri, A. Sadjadi and R. Malekzadeh (2014). "A diversity of cancer incidence and mortality in West Asian populations." Annals of global health 80(5): 346-357.

24. Chen, B., C. Hong and H. Kan (2004). "Exposures and health outcomes from outdoor air pollutants in China.” Toxicology 198(1-3): 291-300.

25. Fritschi, L. and T. Driscoll (2006). "Cancer due to occupation in Australia." Australian and New Zealand journal of public health 30(3): 213-219.

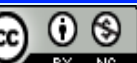

This work is licensed under a Creative Commons AttributionNon Commercial 4.0 International License. 